\title{
Correlation Between Coupling Metrics Values and Number of Classes in Multimedia Java Projects: A Case Study
}

\author{
Mr. V. S. Bidve', Dr. P. Sarasu ${ }^{2}$ \\ ${ }^{I}$ Ph.D. Scholar, ${ }^{2}$ Director $R \&$ D, Veltech Dr. RR \& Dr. SR Technical University, Avadi, Chennai, India
}

\begin{abstract}
Coupling is an interdependence relationship between the modules of object-oriented software. It is a property with the most influence on quality attributes of the object-oriented software. Coupling with high values results in complex software design hence software professionals try to keep the coupling as low as possible. The values of coupling metrics are dependent on the type of input source code. Reusability is the main feature of object-oriented languages, so coupling occurs due to reuse of code modules. This paper investigates a correlation between the values of coupling metrics and the number of classes in the multimedia Java code. Here, a case study of a banking multimedia Java project with its forty different versions is conducted to comments on this correlation. The analysis of the results shows that, if the input source code is with a large number of classes then it results in high coupling values.
\end{abstract}

Keywords - Coupling, Object-oriented, Metrics, Classes, Software.

\section{INTRODUCTION}

Ooftware coupling is an important metrics from the quality point

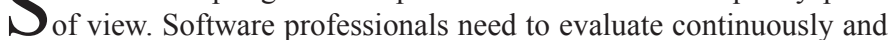
study relations and correlations of all attributes and factors that can affect their developed software products [1]. Software metrics values are the indicators of one or more software quality attributes. Coupling metrics values are also the indicators different quality attributes like reliability, efficiency, integrity, maintainability, flexibility, portability, reusability, and interoperability, etc. [2], [3], [4].

In this paper, we focused on studying the correlation between coupling metrics values and the total number of classes in multimedia Java projects. The focus of this study is to monitor the behavior of coupling values with raise in numbers of classes of multimedia Java projects. The study considers banking software named Cyclos with its forty different versions downloaded from the open source repository sourceforge.net. The versions of Cyclos taken into account for this study possess the different number of classes and coupling values.

The rest of the paper is organized as follows. In section 2 data collection for the case study is given. Section 3 provides detailed of results and analysis. The correlation analysis between coupling metrics values and number of classes in input multimedia Java code is provided in section 4 . Section 5 concludes the paper.

\section{Data Collection for the Case Study}

This section gives details of input multimedia Java projects, selection of coupling metrics, coupling data collection procedure used in the work.

\section{A. Input multimedia Java projects}

This study considers the projects developed in multimedia Java programming language. The requirement of the input multimedia Java projects is a folder containing .java files. The multimedia Java project folders with .exe or .jar files are not useful for this study. This study referred the open-source repository sourceforge.net to download the multimedia Java projects. The sourceforge.net repository has ten different category projects. This study selected the projects only from the Banking category. The Banking project Cyclos with its forty different versions is considered for this case study. Cyclos offers a complete on-line banking system with additional modules such as e-commerce and communication tools. Cyclos is used for Microfinance institutions, local banks (in developing countries) and complementary currency systems like LETS, Barter networks, and Timebanks. The detailed listing of forty versions of Cyclos is given in Table II.

TABLE I

COUPLING METRICS

\begin{tabular}{|c|c|c|c|c|}
\hline $\begin{array}{l}\text { Sr. } \\
\text { No. }\end{array}$ & Coupling Metrics & Type of interactions & Coupling Mechanisms & Source \\
\hline 1 & Parameter coupling & Method-Method, & $\begin{array}{l}\text { The method of one class invokes method/passes parameter/passes message to methods of } \\
\text { another class or to make a call to the constructor of another class. }\end{array}$ & {$[5]$} \\
\hline 2 & Inheritance coupling & Class-Class & One class is a superclass of another class (Inheritance). & $\begin{array}{l}{[5,6,} \\
7,8]\end{array}$ \\
\hline 3 & Global coupling & $\begin{array}{l}\text { Method-Attribute/Class- } \\
\text { Attribute (Friend) }\end{array}$ & $\begin{array}{l}\text { The method of one class can directly access parts of the internal structure, of another class } \\
\text { method (friend). Also to access common, shared, non-local variables of another class. }\end{array}$ & {$[5]$} \\
\hline 4 & $\begin{array}{l}\text { Data Abstraction } \\
\quad \text { Coupling }\end{array}$ & $\begin{array}{l}\text { Class-Method/Class- } \\
\text { Attribute }\end{array}$ & $\begin{array}{l}\text { One class is used in the implementation of methods of another class. One class is the } \\
\text { domain of the instance variable, the local variable of another class. }\end{array}$ & {$[8]$} \\
\hline 5 & Import Coupling & ALL & All type of coupling due to any import mechanism. & [9] \\
\hline 6 & Export Coupling & ALL & All type of coupling due to an export mechanism. & [9] \\
\hline
\end{tabular}


TABLE II

COUPLING VALUES OBTAINED FROM JCMT

\begin{tabular}{|c|c|c|c|c|c|c|c|c|}
\hline Project Name & $\begin{array}{c}\text { Number of } \\
\text { Classes in } \\
\text { Project }\end{array}$ & $\begin{array}{c}\text { Parameter } \\
\text { coupling }\end{array}$ & $\begin{array}{l}\text { Inheritance } \\
\text { Coupling }\end{array}$ & $\begin{array}{l}\text { Global } \\
\text { Coupling }\end{array}$ & $\begin{array}{c}\text { Data } \\
\text { Abstraction } \\
\text { Coupling }\end{array}$ & $\begin{array}{c}\text { Import } \\
\text { Coupling }\end{array}$ & $\begin{array}{c}\text { Export } \\
\text { Coupling }\end{array}$ & $\begin{array}{l}\text { External } \\
\text { Coupling }\end{array}$ \\
\hline cyclos_3.0 & 1095 & 6884 & 1902 & 10 & 4004 & 4684 & 4680 & 22 \\
\hline cyclos_3.0.1 & 1096 & 6888 & 1904 & 10 & 4007 & 4688 & 4684 & 22 \\
\hline cyclos_3.0.2 & 1095 & 6862 & 1904 & 10 & 3995 & 4665 & 4661 & 22 \\
\hline cyclos_3.0.5 & 1098 & 6937 & 1907 & 10 & 4018 & 4706 & 4702 & 22 \\
\hline cyclos_3.0.6 & 1098 & 6950 & 1907 & 10 & 4022 & 4716 & 4712 & 22 \\
\hline cyclos_3.0.7 & 1098 & 7004 & 1907 & 10 & 4024 & 4732 & 4728 & 22 \\
\hline cyclos_3.0.8 & 1098 & 7008 & 1909 & 10 & 4029 & 4741 & 4737 & 22 \\
\hline cyclos_3.0.B1 & 990 & 5624 & 1716 & 10 & 3526 & 3853 & 3849 & 21 \\
\hline cyclos_3.0.B2 & 1040 & 6254 & 1799 & 10 & 3748 & 4285 & 4281 & 21 \\
\hline cyclos_3.5 & 1809 & 14438 & 3232 & 77 & 7442 & 9946 & 9953 & 28 \\
\hline cyclos_3.5.1 & 1809 & 14449 & 3232 & 77 & 7449 & 9959 & 9966 & 28 \\
\hline cyclos_3.5.2 & 1812 & 14485 & 3238 & 79 & 7475 & 9985 & 9992 & 28 \\
\hline cyclos_3.5.3 & 1812 & 14546 & 3238 & 80 & 7486 & 10019 & 10026 & 28 \\
\hline cyclos_3.5.4 & 1819 & 14608 & 3253 & 81 & 7524 & 10079 & 10086 & 28 \\
\hline cyclos_3.5.5 & 1820 & 14631 & 3255 & 81 & 7531 & 10091 & 10098 & 28 \\
\hline cyclos_3.5.RC1 & 1755 & 13726 & 3126 & 65 & 7162 & 9474 & 9485 & 29 \\
\hline cyclos_3.5.RC1a & 1754 & 13725 & 3126 & 65 & 7161 & 9473 & 9484 & 29 \\
\hline cyclos_3.5.RC2 & 1768 & 14111 & 3154 & 67 & 7303 & 9669 & 9678 & 29 \\
\hline cyclos_3.6 & 2357 & 16615 & 4459 & 109 & 8937 & 11544 & 11573 & 30 \\
\hline cyclos_3.6.1 & 2367 & 16711 & 4466 & 111 & 9026 & 11637 & 11666 & 29 \\
\hline cyclos_3.6.beta1 & 1936 & 15714 & 3487 & 106 & 8107 & 10889 & 10897 & 28 \\
\hline cyclos_3.6.beta2 & 1935 & 15718 & 3485 & 106 & 8110 & 10911 & 10919 & 28 \\
\hline cyclos_3.6.beta3 & 1936 & 15617 & 3491 & 107 & 8069 & 10840 & 10848 & 28 \\
\hline cyclos_3.6.RC1 & 2035 & 16978 & 3659 & 110 & 8558 & 11873 & 11899 & 29 \\
\hline cyclos_3.6.RC2 & 2357 & 16615 & 4460 & 109 & 8944 & 11561 & 11590 & 30 \\
\hline cyclos_3.7 & 2435 & 17275 & 4602 & 123 & 9552 & 12018 & 12062 & 30 \\
\hline cyclos_3.7.1 & 2438 & 17320 & 4606 & 125 & 9569 & 12057 & 12101 & 30 \\
\hline cyclos_3.7.2 & 2443 & 17405 & 4615 & 125 & 9600 & 12113 & 12157 & 30 \\
\hline cyclos_3.7.3 & 2443 & 17403 & 4617 & 125 & 9602 & 12109 & 12153 & 30 \\
\hline cyclos_3.7_RC1 & 2431 & 17253 & 4599 & 123 & 9537 & 11994 & 12038 & 30 \\
\hline
\end{tabular}




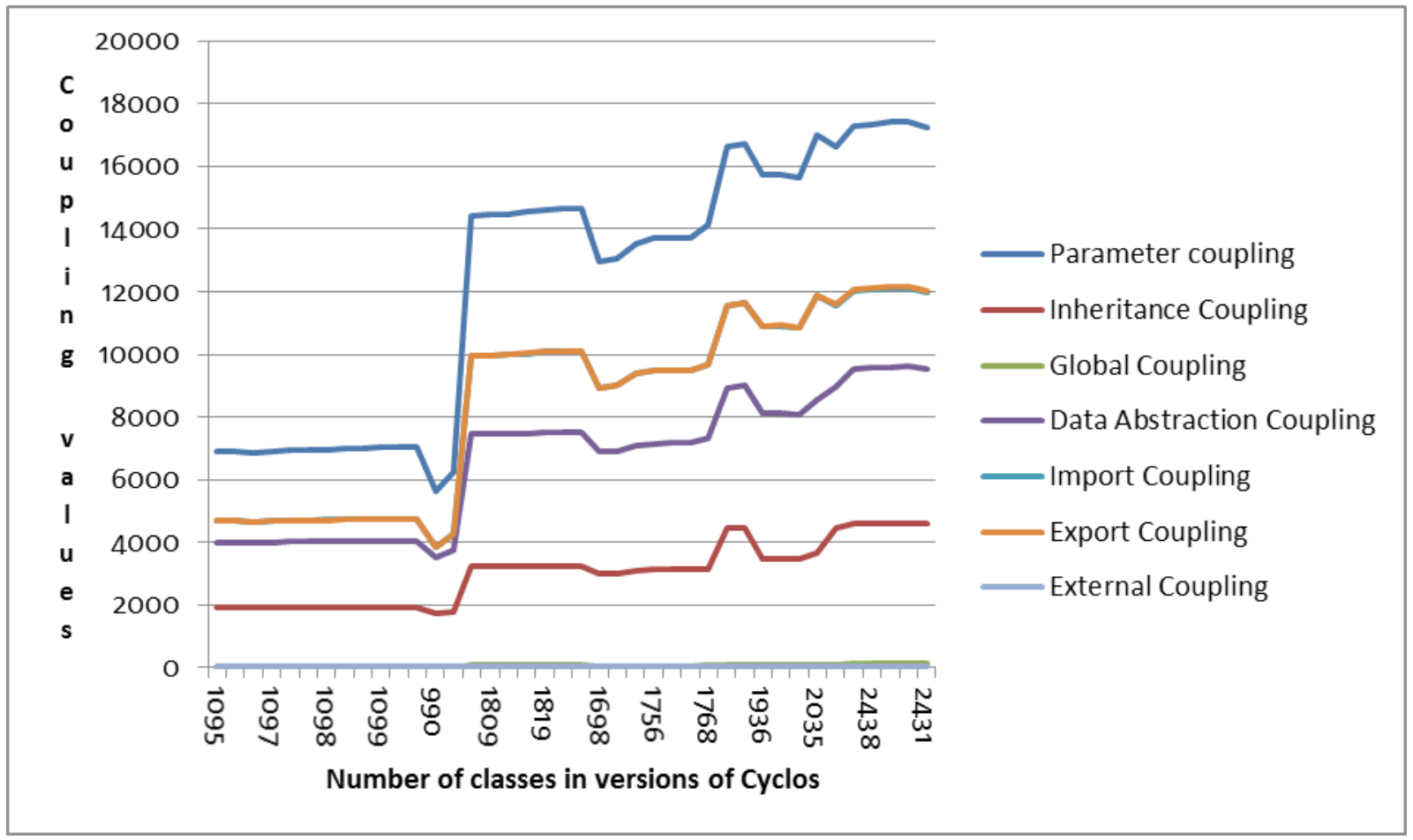

Fig. 1 Behavior of coupling values of forty versions of Cyclos

\section{B. Selection of coupling metrics}

So far, there are many coupling metrics described in the literature by various authors. Every author has a diverse set of coupling metrics focusing on different aspects of coupling measurement. In this study, we considered seven coupling metrics as given in Table I. The metrics selected in this study are comprehensive and considers all aspects of coupling measurement. Every coupling metric chosen for the study have the entirely different type of coupling interactions and mechanisms. The coupling metrics considered is a part of our previous study.

\section{Coupling data collection}

The authors have developed a specific tool named Java Coupling Measurement Tool (JCMT) to compute coupling between all pairs of classes of the input multimedia Java source code. The multimedia Java project folder possessing .java files is an input required to the JCMT tool. The JCMT calculates the seven types of couplings described in Table I.

\section{ResulTS AND ANALYSIS}

In this study, forty different versions of a Banking project Cyclos are evaluated using JCMT to compute values of coupling metrics described in Table I. The sum of the coupling values of all classes belonging to a project is calculated for each coupling metrics by JCMT. The coupling values of forty versions of banking software Cyclos are computed using JCMT and specified in Table II.

The behavior of the coupling values of all forty versions of Cyclos project is plotted using a graph shown in figure 1 .

In figure $1, \mathrm{X}$-axis represents the number of classes and Y-axis represents the coupling values of the different versions of Cyclos project. The curves of import and export couplings are overlapped in figure 1 because of the minor difference in their coupling values. Similarly, the curves of global and external couplings are also overlapped and are near to $\mathrm{X}$ axis because of their smaller coupling values. Primarily from figure 1, it is observed that every coupling metrics has a different range of values but a geometrically similar behavior. Secondly, it seems that the behavior of coupling values is changing as per the number of classes of a project. If the numbers of classes in project increases then coupling metrics values are also increases.

\section{Correlation Analysis}

The correlation analysis aims to determine the relationship between the number of classes and coupling metrics values of a project. The goal of this correlation analysis is to answer the following questions.

Q1. Is there a correlation between the number of classes and coupling metrics values of a project?

Q2. Which correlation exists between the number of classes and coupling metrics values of a project?

To answer the above questions, data of Table II is sorted as per the ascending order of the number of classes in the projects.

The graph is plotted for the values of Table III and presented in figure 2. In figure $2 \mathrm{X}$-axis represents the number of classes in the project and $y$-axis represents coupling metrics values of the Cyclos project.

From the figure 2 following observations are made,

1. As the number of classes in the project increases the coupling values also increases. For e.g. in the version cyclos_3.0.B1, the numbers of classes are 990 means the lowest number of classes, so the project has lowest coupling values. Where, in subsequent projects numbers of classes are increased, so coupling values are also increased. There are some exceptions to this rule, in cyclos_3.0.9 the total classes are increased by one than its earlier version cyclos 3.0.11 in Table II, but the coupling values of cyclos_3.0.9 are smaller or same as compared to its earlier version cyclos_3.0.11. These exceptions happen when there is very small rise in the total number of classes i.e. rise of one to five classes or no rise. If 
TABLE III

DATA OF TABLE 2 SORTED AS PER ASCENDING ORDER OF NUMBER OF CLASSES

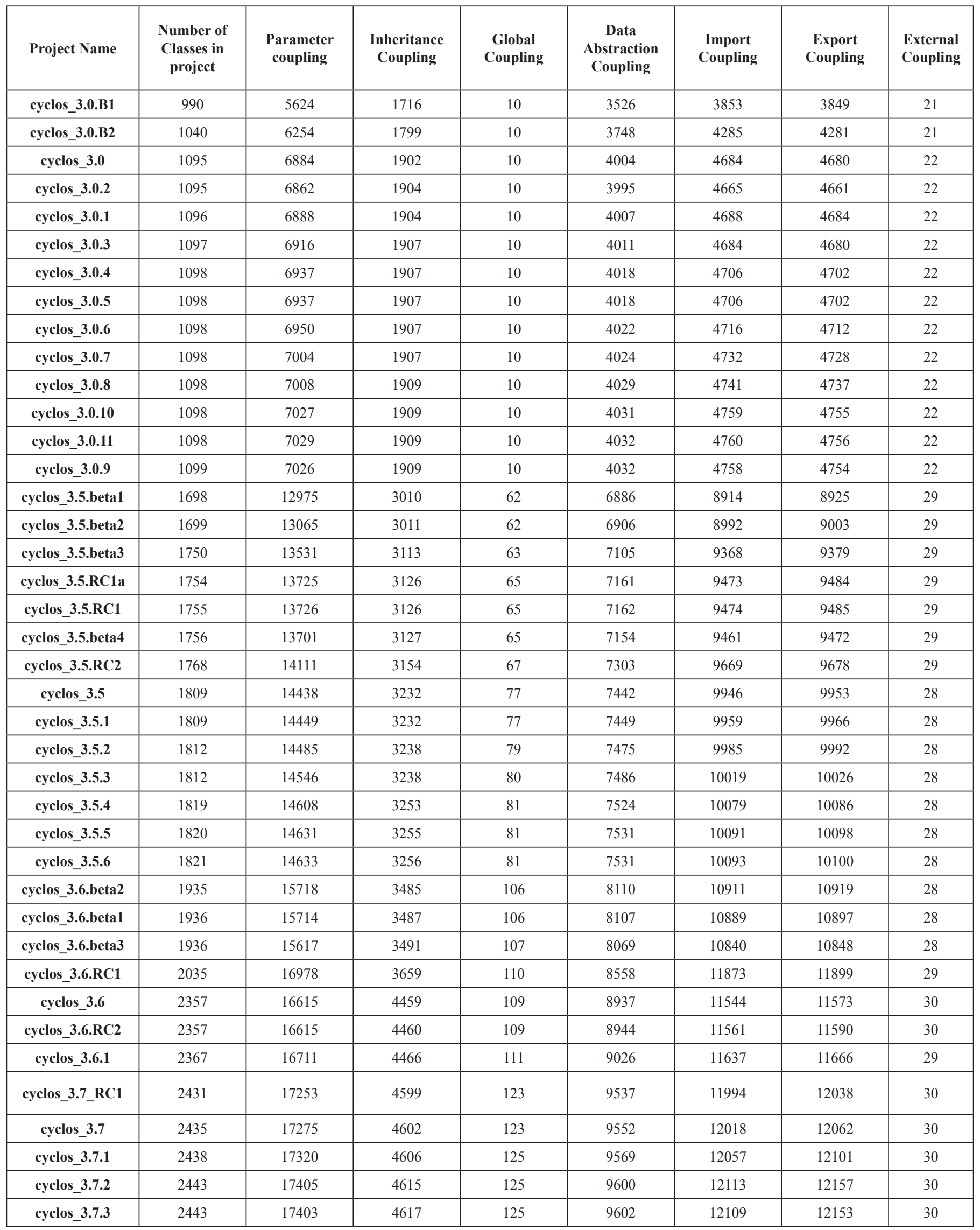




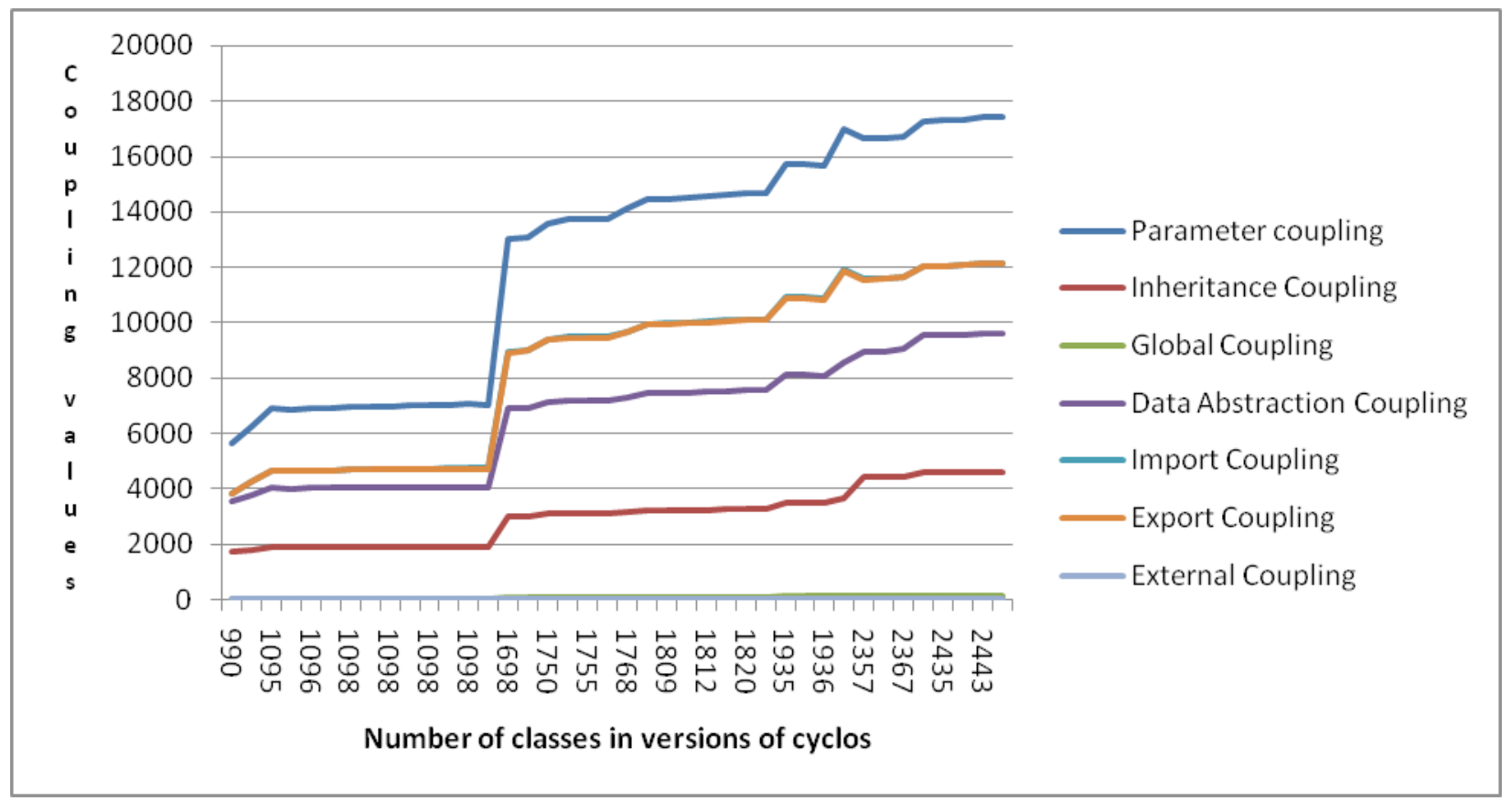

Fig. 2 Behavior of coupling values of forty versions of Cyclos after sorting

there is a major rise (i.e. rise of more than five) in the number of classes of the project, then the coupling values of the projects are increased. It means if there is a major rise in the number of classes of the project the coupling values also increases.

2. Even if the numbers of classes are stable, the coupling values are not stable. From the versions cyclos 3.0.4 to cyclos_3.0.11 it is observed that even if the number of classes is same for multiple versions, the coupling values can differ. This is due to changes in the software as per requirements.

Answer 1. With the above observations, the questions can be answered as below.

Answer 2. The correlation exists between the number of classes and coupling values of the projects.

(1) The second question is answered in two parts.

(2) Numbers of classes in the project are directly proportional to the coupling values of the project in case of the significant rise in the number of classes.

If the numbers of classes are stable for many versions then coupling values of the versions may differ.

\section{Conclusion}

In this paper, a case study is used to find the correlation between the numbers of classes and coupling values of the multimedia Java projects. Results showed that the numbers of classes in the project are directly proportional to the coupling values of the project in case of the major (more than five) rise in the number of classes. Also, if the numbers of classes are stable for many versions, then coupling values of the versions may differ.

\section{REFERENCES}

[1] Arwa Abuasad, Izzat M. Alsmadi, "Evaluating the Correlation Between Software Defect and Design Coupling Metrics", 2012 International Conference on Computer, Information and Telecommunication Systems, CITS 2012, Amman, Jordan. 978-1-4673-1550.

[2] Lucas Batista Leite de Souza, Marcelo de Almeida Maia, "Do Software Categories Impact Coupling Metrics?", Proceedings of the Working
Conference on Mining Software Repositories, pp. 217-220. IEEE 2013.

[3] Marcio F. S. Oliveira, Ricardo Miotto Redin, Luigi Carro, Luis da Cunha Lamb, Flavio Rech Wagner, "Software quality metrics and their impact on embedded software", In 5th International Workshop on Model-based Methodologies for Pervasive and Embedded Software (MOMPES), pages 68-77, 2008.

[4] Yeresime Suresh, Jayadeep Pati, Santanu Ku Rath, "Effectiveness of software metrics for the object-oriented system." Procedia Technology 6 (2012): 420-427.

[5] Jeff Offutt, Aynur Abdurazik, and Steve Schach, "Quantitatively Measuring Object-Oriented Couplings", Springer's Software Quality Journal, 6(4):489-517, December 2008.

[6] J. Eder, G. Kappel, M. Schrefl, "Coupling and Cohesion in ObjectOriented Systems", Technical Report, University of Klagenfurt, 1994.

[7] Huan Li, "A Novel Coupling Metric for Object -Oriented Software Systems", IEEE International Symposium on International Journal of Computer Applications (0975 - 8887) Volume 27- No.10, August 2011Knowledge Acquisition and Modeling Workshop, pp. 609-612, 2008.

[8] Husein Sukainah, Oxley Alan, "A Coupling and Cohesion Metrics Suite for Object-Oriented Software", International Conference on Computer Technology and Development, vol.1, no., pp.421-425, 13-15 Nov. 2009.

[9] Briand, Lionel C., John W. Daly, and Jurgen K. Wust, "A unified framework for coupling measurement in object-oriented systems." Software Engineering, IEEE Transactions on 25.1 (1999):91-121.

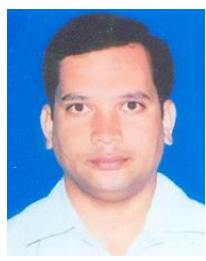

Mr. V. S. Bidve Ph.D. scholar in \#Veltech Dr. RR \& Dr. SR Technical University, Avadi, Chennai, India. Works as a Assistance professor in SKNCOE, Pune. Obtained B.E. in Computer Science and Engineering, and M.Tech. in Information Technology. Has $14+$ years teaching experience. Working in the area software engineering, web technology, Advanced databases etc.

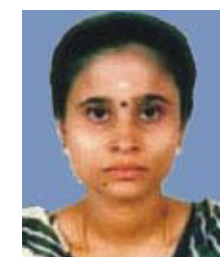

Dr. P. Sarasu. Working as a Research Dean in \#Veltech Dr. RR \& Dr. SR Technical University, Avadi, Chennai, India. Also working as a Research supervisor for Ph.D. scholars. Having 20+ years experience in teaching. Working in the area software engineering, mobile computing, wireless network, Advanced Databases etc. Guiding eight research scholars. 